\title{
Cevat Giray Aksoy* The Effects of Unemployment on Fertility: Evidence from England
}

DOI 10.1515/bejeap-2014-0127

Submitted September 21, 2014; published online February 9, 2016

Abstract: This paper reinvestigates the causal effects of local unemployment on fertility. It argues that contradicting results in the existing empirical research may have arisen due to a neglect of sub-demographic differences and failure to recognize endogeneity. It hypothesizes that male and female unemployment will have different impacts on fertility across subgroups of the population. Drawing on the UK Labor Force Survey and the Birth Statistics data from the Office for National Statistics, the results of this study suggest that female unemployment tends to increase births, whereas male unemployment has the opposite effect. More importantly, the reported results indicate the unemployment and fertility relation exhibits strong variation across demographic subgroups. Lastly, a persistent countercyclical fertility pattern is also documented at the county level.

Keywords: unemployment, fertility

JEL Classification: J13, J19

\section{Introduction}

This paper examines how local unemployment affects household fertility outcomes. The standard economic models of fertility imply that unemployment has a potential offsetting impact on fertility, as it leads to a substantial fall in income. Assuming that children are a normal good, an increase in unemployment will have a negative impact on the demand for children in the current period, holding other factors constant. In societies with traditional gender roles, the income effect can be expected to be the main effect of male unemployment. Conversely, among females, unemployment decreases the opportunity cost of childrearing and may potentially increase birth rates. The final outcome will depend on individuals' expectations of the duration of joblessness and human capital depreciation as well as the strength of the net income effect.

*Corresponding author: Cevat Giray Aksoy, Department of Economics, Royal Holloway University of London, Egham, London TW20 0EX, UK, E-mail: cevat.aksoy.2012@live.rhul.ac.uk 
There is a growing body of literature that investigates the impact of unemployment on household fertility decisions. However, the findings from the existing literature are mixed and occasionally contradictory. ${ }^{1}$ In response, the current paper seeks to clarify the causal impact of unemployment on fertility and to demonstrate how previous mixed results may be due to differences in behavior among demographic subgroups. Ultimately, it concentrates on three key research questions:

1 Is the overall effect of unemployment on current fertility positive or negative?

2 Is the impact different for male and female unemployment and across different age groups? ${ }^{2}$

3 Are there further demographic characteristics that shape the fertility response to unemployment? ${ }^{3}$

The current paper builds on the recent contribution by Schaller (2015) who, using US data, explicitly considers the role of gender-specific labor market conditions on fertility. It consequently reexamines the relationship between unemployment and fertility using English data with a particular focus on demographic subgroups. The main analysis starts with an estimation of a fixed effects model where current fertility by county and year is related to lagged unemployment while controlling for demographic characteristics and house prices. This is followed by a breakdown of the overall relationship by gender-specific unemployment and by age group. In order to address the potential endogeneity issue, an instrumental variables (IV) strategy is implemented based on the approach of Bartik (1991), in which labor demand shocks are used as an identifying source of variation. Although aggregate local unemployment leads to an increase in fertility, the analysis reveals important difference across demographic subgroups. ${ }^{4}$ In particular, both the ordinary least squares (OLS) and IV estimations show that for the prime-aged cohort (25-34), male unemployment is negatively associated with the fertility, whereas female unemployment has a positive effect on birth rates. The results tend in a similar direction among the younger age group of 16-24, where male unemployment appears to have a negative impact on the current period fertility, while female unemployment has the opposite

1 See Sobotka, Vegard, and Philipov (2011) for a review of the earlier literature.

2 16-24 male, 25-34 male, 35-44 male, 16-24 female, 25-34 female, 35-44 female.

3 Educational attainment, country of birth and marital status.

4 The countercyclical fertility behavior supports the predictions of Butz and Ward's (1979) model. They argue that as female employment rate increases in a country, negative labor demand shocks significantly reduce the cost of childbearing and women take advantage of this "joblessness" term. 
effect. These main findings are in line with the theoretical prediction outlined above. In addition, particular demographic factors differentially shape the fertility response across age groups. Specifically, education, country of birth and partnership status mediate the relationship between prime-aged individuals' labor market conditions and fertility more than that between youth labor market conditions and fertility.

The present paper thus sheds light on the mixed results in the existing literature, particularly showing how the relationship between unemployment and fertility varies across demographic subgroups. First and foremost, there are strong reasons to expect that the relationship between unemployment and fertility may vary across age groups. Second, in order to disentangle the effect of gender-specific unemployment, it is important to control for both male and female unemployment simultaneously. Finally, the current paper also contributes to the existing literature by tackling the issue of endogeneity using a Bartik-style IV approach.

The paper proceeds with an initial section introducing the conceptual framework and related literature. Section 3 subsequently focuses on data and methodology while Section 4 presents the results, and Section 5 concludes.

\section{Conceptual Framework and Related Literature}

In recent years, there have been a number of contributions exploring the cyclical nature of fertility. These studies show that the fall in fertility rates coincides with higher levels of female unemployment (Brewster and Rindfuss 2000; EspingAndersen 2009; Engelhardt and Prskawetz 2004). The standard theoretical framework typically put forward builds on the work of Becker (1960) and depicts couples as utility-maximizing agents deciding on the number of children and on child-related expenditures. In this respect, two main approaches introduced children as a normal good into economic models of fertility. The quality and quantity approach (Becker 1960; Becker and Lewis 1973; Willis 1973) implies that an increase in income may have depressing effects on fertility. It relies on the fact that income elasticity for the number of children is substantially less than that for quality of children. ${ }^{5}$ The timing of the fertility approach (Mincer 1963; Becker 1960) attributes the low opportunity cost of childrearing during recessions, which could imply a positive relationship between unemployment and

5 Becker (1960) altered his model and added a "quality" variable in order to explain the observed inverse relationship between income and fertility. However, Jones, Schoonbroodt, 
fertility. Where "traditional" gender roles exist, the main effect of male unemployment can be expected to be the income effect. Conversely, female unemployment can be expected to have both a negative income effect and a potentially positive opportunity cost effect. In other words, an increase in male unemployment may lead to a fall in fertility. ${ }^{6}$ While a rise in female unemployment may also cause a decline in fertility, it nevertheless has a potential substitution effect that goes in the direction of increasing births as opportunity cost becomes lower. ${ }^{7}$

In terms of the female income effect on fertility, previous studies appear to show that women choose to have fewer children as a result of an increase in the economic costs of childrearing (Easterlin 1973; Mincer 1963). This may occur because the "female time intensity" of children is still a key component in the price of fertility, and because the costs of having children for their careers and lifecycle income are substantial. In fact, it has been shown that the unemployment duration of a woman in the labor force is affected by her previous work experience and her lifetime allocation of time, which in turn is intimately related to her fertility decisions (Mincer 1963). An additional determinant affecting ideal timing of fertility is human capital depreciation. It may be argued that most women's human capital investment in schooling is completed before childrearing starts, and thus the cost of childrearing may also be related to women's educational attainment and to their employment possibilities. $^{8}$

Schaller (2015) provides a recent examination of this issue and investigates the differential impacts of male and female unemployment on fertility. Her

and Tertilt (2008) show that without assuming a high elasticity of substitution between children and consumption, the quality-quantity approach does not sufficiently explain an inverse income-fertility relationship.

6 Kravdal (2002) takes the discussion further and suggests that unemployed men are less attractive as a potential husband for the family formation, which may also reduce the possibility of fertility.

7 Some papers in the literature focus on how fertility rates are affected by an exogenous change in household income. For example, Lindo (2010) shows that birth rates are negatively affected by lower household income due to job loss. Black et al. (2013) show that the 1970s coal boom in West Virginia caused an unexpected increase in income, which also led to an increase in fertility.

8 Heckman and Walker (1990) estimated semi-parametric reduced-form neoclassical models of life cycle fertility in Sweden and showed that rising female wages delay times to all conceptions and reduce total conceptions. Happel, Hill, and Low (1984) also argued that human capital accumulation is an important determinant of fertility timing. 
results show that although birth rates follow a pro-cyclical pattern at the aggregate level in the United States, improvements in male labor market conditions are associated with increases in fertility, whereas improvements in female labor market conditions have the opposite effect. She also performs a particular examination of the demographic subgroups. Based on her analysis, the negative effect of unemployment becomes more pronounced for older people. Furthermore, single women and lower educated groups are highly impacted by the business cycles. The present paper shares with Schaller (2015) the emphasis on gender specific unemployment and demographic subgroup differences as a key determinant of the fertility outcome. An important difference is this paper additionally investigates how further demographic characteristics affect the unemployment-fertility relationship within age groups with different demographic characteristics, whereas Schaller (2015) does not make this distinction. Another contribution of my analysis comes from the fact that I can take house price changes into account. Recent evidence suggests that short-term increases in local house prices affect the fertility of home-owners positively but that of non-home-owners negatively in the United States (Dettling and Kearney 2014). Moreover, special attention should be devoted to England, because it exhibits different labor market properties from those of the United States, namely a considerable increase in female labor force participation (LFP) and a more rapid closing of the gender wage gap. ${ }^{9}$

The results in the literature so far are mixed and difficult to reconcile. Karaman Örsal, Dilan and Goldstein (2010) show a negative effect of both male and female unemployment on current fertility rates in 1976-2008 across 22 OECD (Organization for Economic Co-operation and Development) countries. A number of recent papers report findings that countries with higher female unemployment have lower number of births since the early 1990s (Adsera 2005; Ahn and Mira 2002; Brewster and Rindfuss 2000). In contrast, Ozcan, Mayer, and Luedicke (2010) show that the male unemployment delays the first birth, but female unemployment does not affect fertility in West Germany. Overall, these studies thus highlight the need for further systematic examination of the unemployment and fertility phenomenon.

\footnotetext{
9 In England, the difference between the participation rate of men and women has shrunk remarkably from 14.5 percentage points in 1994 to 8.6 percentage points in the final quarter of 2011. Polachek and Xiang (2014) show that the gender wage gap is declining relatively more quickly in England - along with Canada and Korea - than in other countries.
} 


\section{Data and Methodology}

The principal empirical methodology of this paper involves relating county-level fertility rates to lagged county-level unemployment rates and to control for timevarying county-level demographic characteristics. The following section briefly explains the main data sources and how the relevant variables are constructed.

\subsection{Data}

The fertility data used in this analysis come from the Office for National Statistics (ONS). It compiles counts of live births and stillbirths by age of mother and area of usual residence in England, years 1995-2011. Age-specific fertility rates (ASFRs) are constructed by dividing the number of births by the relevant female population using mid-year population estimates that are based on the censuses, in which female ages range between 16 and $44 .{ }^{10}$ ASFRs provide an appropriate measure of varying fertility rates since they are unaffected by changes in population age distribution and are well suited for comparing fertility rates across age groups. In this analysis, ASFRs are based on age intervals of $16-24,25-34$ and $35-44 .{ }^{11}$ As the best available measure of the labor market conditions prevailing at the time of the conception, births in calendar year, $t$, are matched with 1 year lagged, $t-1$, data of Labor Force Survey (LFS) in the corresponding county. ${ }^{12}$

10 Age-gender cohorts are as follows: 16-24 male, 16-24 female, 25-34 male, 25-34 female, 3544 male, 35-44 female.

11 The ONS's age grouping is utilized in this analysis.

12 Both Birth Statistics and LFS data are available in a finer geography; however, due to small cell size in some areas, it was preferred to aggregate up to the ceremonial county level. There are 49 ceremonial counties in England. After the exclusion of the City of London and Rutland the remaining ceremonial counties are as follows: Bedfordshire, Berkshire, Bristol, Buckinghamshire including Milton Keynes, Cambridgeshire including Peter-borough, Cheshire consisting of Cheshire East, Cheshire West and Chester, Halton and Warrington, Cornwall including Isles of Scilly, Cumbria, Derbyshire including Derby, Devon including Plymouth and Torbay, Dorset including Bournemouth and Poole, County Durham including Darlington, Hartlepool and Stockton-on-Tees north of the River Tees, East Riding of Yorkshire, including Kingston-uponHull, East Sussex including Brighton and Hove, Essex including Southend-on-Sea and Thurrock, Gloucestershire including South Gloucestershire, Inner and Outer London, Greater Manchester, Hampshire including Portsmouth and Southampton, Herefordshire, Hertfordshire, Isle of Wight, Kent including Medway, Lancashire including Blackburn with Darwen and Blackpool, Leicestershire including Leicester, Lincolnshire including North Lincolnshire and North East Lincolnshire, Merseyside, Norfolk, North Yorkshire including Middlesbrough, Redcar and Cleveland, York and Stockton-on-Tees south of the River Tees, Northamptonshire, Northumberland, Nottinghamshire including Nottingham, Oxfordshire, Shropshire including 
Access to the confidential LFS was vital to conduct this study, as it was used to construct county-year-age group-specific unemployment rates and countyyear-age group-specific demographic characteristics. The sample is restricted in the age band 16-44 in order to study females who are of childbearing ages. ${ }^{13}$ Table 1 presents the descriptive statistics for demographic characteristics and unemployment rates from the LFS, birth statistics from the ONS and house prices from the Department for Communities and Local Government. ${ }^{14}$

Figure 1 illustrates fertility and unemployment patterns among counties. Northumberland, Cheshire and Dorset have the lowest average fertility rates in England and the South East region along with the Greater London experience the highest fertility. Merseyside, Tyne and Wear and West Midlands are the areas with the highest unemployment rate over the sample period.

Figure 2 shows trends in birth rates and unemployment rates by age groups at the national level. ${ }^{15}$ Birth rates follow a decreasing trend for age group 1 after reaching a peak of 53.2 births per 1,000 women in 1995. With regard to the 25-34 band, birth rates rebounded after 2000 and reached its highest point of 112.2 in 2009. The oldest age group, 35-44, has experienced a tremendous rise in fertility rate, a steady increase from 21.3 to 35 . Turning to the national time series data for unemployment rates, they notably differ in levels across age groups but follow a similar trend. The total unemployment rate reached its lowest point between 2002 and 2005, and gradually increased afterwards. Overall, substantial variation across counties in Figure 1 and considerable shift in birth trends across age groups in Figure 2 strongly suggest the inclusion of county-specific and age group-specific linear time trends. Additionally, from looking at the figure, birth rates appear to follow a countercyclical pattern over the analyzed time interval.

In all, a balanced panel is constructed for the 1994-2010 period, with 47 counties and three age groups. The final version of the dataset contains

Telford and Wrekin, Somerset including Bath and North East Somerset and North Somerset, South Yorkshire, Staffordshire including Stoke-on-Trent, Suffolk, Surrey, Tyne and Wear, Warwickshire, West Midlands, West Sussex, West Yorkshire, Wiltshire including Swindon, Worcestershire.

13 Over the sample period, the median age difference between husband and wife was 2.1 years. Furthermore, only $6.4 \%$ of men and $3.4 \%$ of women who married since 1995 were more 10 years older than their spouse.

14 All unemployment rates are based on the ILO definition (those who are out of work in the reference week, want a job, have actively sought work in the last 4 weeks and are available to start work within the next 2 weeks).

15 Trends in age-gender-specific unemployment rates do not distinctly differ from that of their age group counterparts. 
Table 1: Summary statistics.

\begin{tabular}{lrr}
\hline Variables & Mean & Standard deviation \\
\hline Birth rates by age group & & \\
Aged 16-24 & 48.69 & 8.705 \\
Aged 25-34 & 99.61 & 11.23 \\
Aged 35-44 & 27.74 & 7.689 \\
Unemployment by age group & & \\
Aged 16-24 & 13.40 & 4.512 \\
Aged 25-34 & 5.772 & 5.314 \\
Aged 35-44 & 4.197 & 2.064 \\
Unemployment by age group and gender & & \\
Female aged 16-24 & 11.46 & 4.450 \\
Female aged 25-34 & 5.207 & 2.476 \\
Female aged 35-44 & 3.961 & 1.861 \\
Male aged 16-24 & 15.09 & 5.604 \\
Male aged 25-34 & 5.922 & 3.582 \\
Male aged 35-44 & 4.384 & 2.790 \\
Single & 0.500 & 0.060 \\
Married & 0.418 & 0.058 \\
Divorced/widowed & 0.082 & 0.014 \\
UK born & 0.910 & 0.071 \\
Non-UK born & 0.090 & 0.043 \\
White & 0.931 & 0.077 \\
Other ethnicities & 0.090 & 0.058 \\
Higher education & 0.238 & 0.061 \\
Further education & 0.245 & 0.028 \\
Compulsory education or less & 0.517 & \\
House prices & 2,397 & \\
$N$ & 4112,045 \\
\hline
\end{tabular}

Notes: The table provides within cell means for 47 counties used in the baseline specification. House prices are CPI adjusted to 2005 pounds.

information on ASFRs, age- and gender-specific unemployment rates, educational attainment, marital status, ethnicity and country of birth.

\subsection{Methodology}

In order to obtain baseline estimates of the relationship between unemployment and fertility, the following fixed effect specification is employed:

$$
\ln \left(Y_{g c t}\right)=\beta U_{g c}(t-1)+\psi X_{g c}(t-1)+\alpha_{c}+\theta_{g}+\gamma_{t}+\omega_{c} \times T+\delta_{g} \times T+\varepsilon_{g c t}
$$




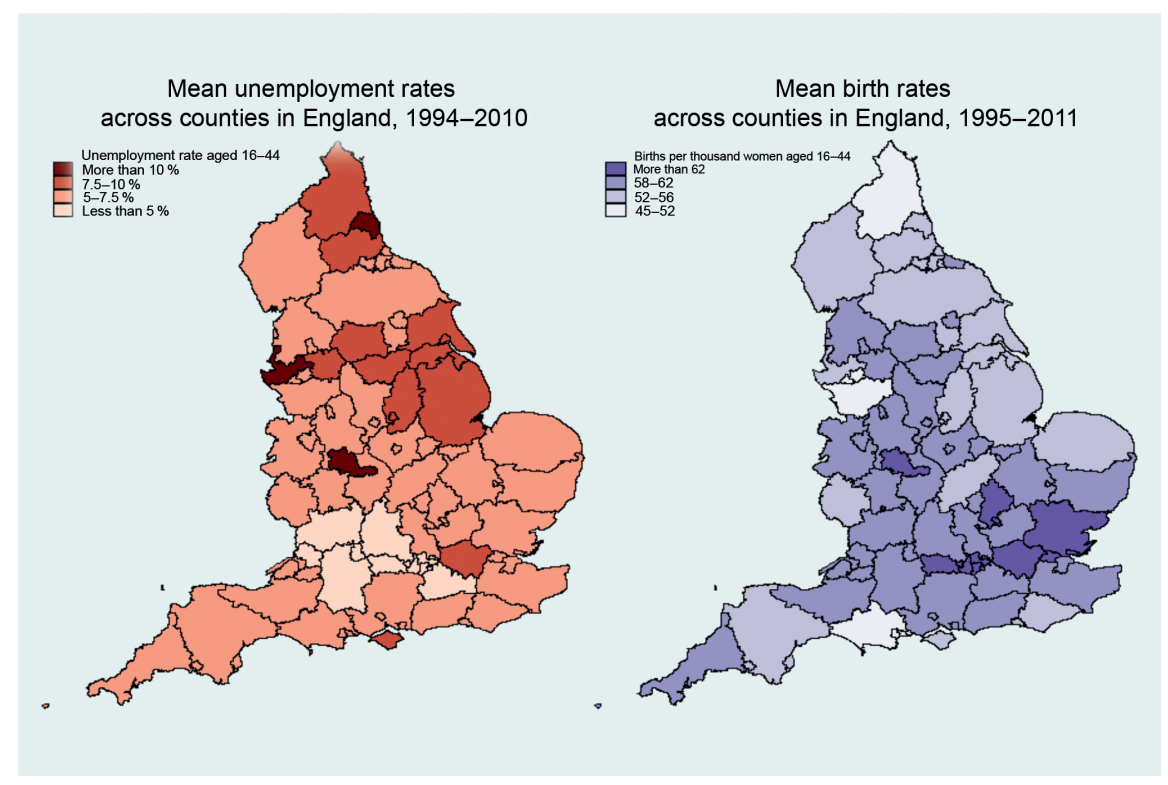

Figure 1: Mean unemployment rates and mean birth rates across counties in England.
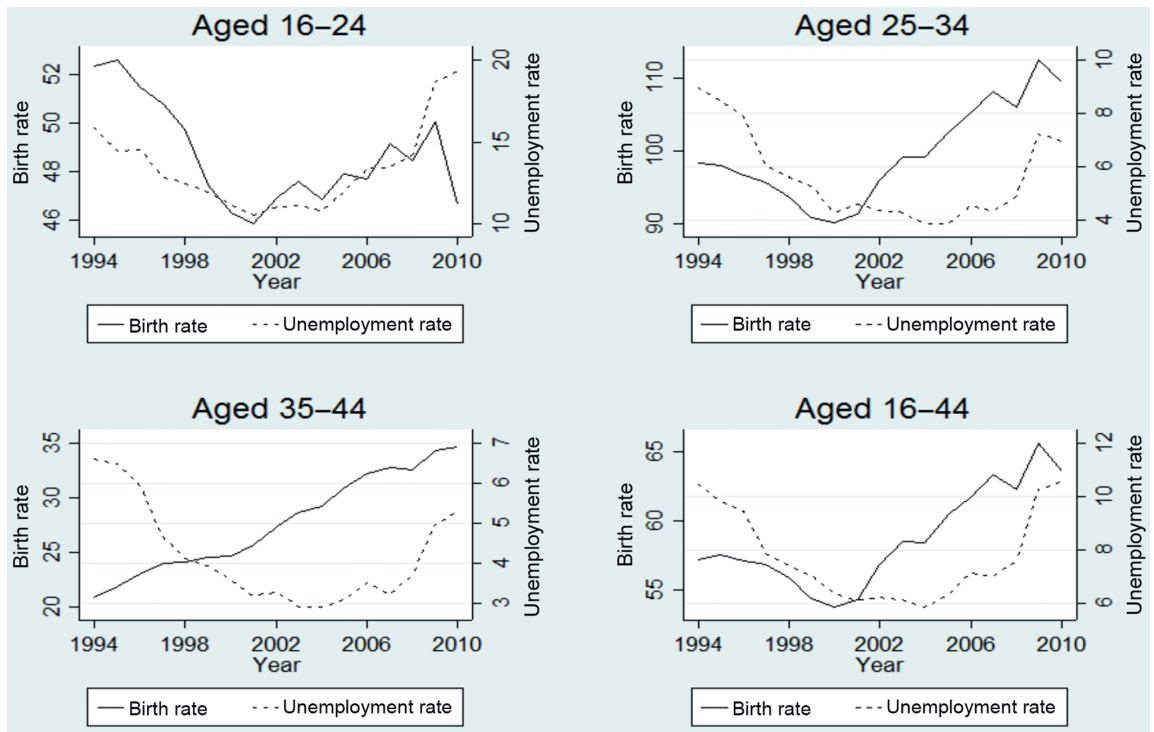

Figure 2: Age-specific unemployment rates and age-specific fertility rates in England. 
The level of analysis is a county-year-age group cell. $Y_{g c t}$ is the birth rate in county $c$, age group $g$, in year $t$ and $U_{g c(t-1)}$ is the lagged unemployment rate. ${ }^{16}$ The county fixed effects, $\alpha_{c}$, and age group fixed effects, $\theta_{g}$, are included to control for differences in birth rates across counties and age groups owing to time-invariant unobservable factors. The year fixed effects, $\gamma_{t}$, account for movements in fertility rates over time that are shared by all counties. The countyspecific linear time trends, $\omega_{c} \times T$, and age group-specific linear time trends, $\delta_{g} \times T$, control for unobserved variables correlated with birth rates that change linearly over time within counties and age groups. ${ }^{17} X_{c(t-1)}$ indicates lagged time-varying county-level demographic controls (country of birth, ethnicity, educational attainment and marital status) and house prices that account for changes in population composition and changes in the real estate market. The regressions are simultaneously carried out for both male and female unemployment in own age group. ${ }^{18}$ All regression are weighted by the relevant population of women in each cell.

This study uses the identification assumption that local unemployment rates are conditionally exogenous to household fertility outcomes. However, there are certain concerns associated with the use of unemployment rates as exogenous regressors. One of these is that local unemployment rates might be correlated with changes in other unobserved variables that may affect the fertility decision of individuals. Second, there may be a positive correlation between fertility and local labor supply. If birth rates increase due to the changes in local labor supply, then the unemployment measure may be picking up this relationship rather than the effect of local labor market demand. Lastly, the International Labour Organization (ILO) definition of unemployment may not be able to capture the full extent of the local labor market conditions, causing a measurement error. The estimation strategy to deal with these problems is to specify a variable that can account for demand-induced variation in unemployment, and can thus be used to obtain an unbiased estimate of the effect of unemployment on fertility. To this end, the IV approach was adopted to explore the robustness of the OLS results. The predicted unemployment rates were built based on the work of Bartik (1991), Blanchard and Katz (1992), Schaller (2015) and Anderberg et al. (2015) for the UK case, where the initial industry composition of employment is interacted with the corresponding national industry-specific trends in

16 To be precise; $t-1$ refers to the year of conception.

17 The inclusion of county-specific quadratic time trends was proved to be unimportant.

18 The analysis for the age-gender-specific unemployment was performed with a similar specification in which both lagged male -MaleUnemp $\mathrm{g}_{g(t-1)}$ - and female -FemaleUnemp $\operatorname{sc}_{c(t-1)}$ unemployment rates are included in the same regression. 
unemployment. In particular, the local industry composition by gender and age group at baseline, defined as the calendar year 1993, is combined with industryspecific unemployment rates by gender, age group and time at the national level over the sample period. ${ }^{19}$ For each county, age group, gender and year industrypredicted unemployment rates are constructed as follows:

$$
\text { Predicted Unemp } \mathrm{ghjt}=\sum_{k} \Psi_{\text {ghjk }} \mathrm{UNEMP}_{\text {ghkt }}
$$

where $\psi_{\text {ghjk }}$ is the share of industry $k$ among employed individuals of age group $g$, gender $h$, county $j$ at baseline, and where UNEMP $_{\text {ghkt }}$ is the unemployment rate, at the national level, in industry $k$ for individuals of age group $g$, gender $h$ and in time period $t$. Given that the predicted unemployment measure is a weighted average of the national industry-specific unemployment rates, these weights reflect the baseline local industry composition in the relevant gender and age group.

The IV approach has a number of attractive features. Most importantly, the estimates cannot be affected by contemporaneous omitted variables since the only local input into the predicted unemployment rates is the industry structure at baseline and these rates cannot be related to any contemporaneous (during the sample period) omitted variables. Furthermore, as mentioned earlier, birth rates in a county are a function of both local labor supply and labor demand. It is for this reason that the use of observed changes in local labor market confounds the results. Instead, the IV uses labor demand shocks as an identifying source of variation and act as an exogenous change in local labor demand. Additionally, the predicted unemployment rate during the next period relies only on initial local industry composition and national-level industry-specific unemployment rates that influence the gender composition of employment opportunities. However, one might be concerned for the earlier time periods of the panel. Later in this paper, this issue is investigated by dropping some of the years at the beginning of the sample period from the estimated model. This

19 Eight industries are used in the analysis based on a condensed version of the UK Standard Industrial Classification of Economic Activities, SIC (2007): “Agriculture, forestry, fishing, mining, energy and water supply", "Manufacturing”, "Construction”, "Wholesale, retail \& repair of motor vehicles, accommodation and food services", "Transport and storage, Information and communication", "Financial and insurance activities, Real estate activities, Professional, scientific \& technical activities, Administrative \&support services", "Public admin and defense, social security, education, human health \& social work activities", "Other services". The "industry unemployment rate" is defined as the unemployed by industry of last job as percentage of economically active by industry. 
estimation does not send any warning signals that the main results are substantially affected by underlying serial correlation in county-specific circumstances.

\section{Results}

\subsection{OLS Specifications}

Table 2 presents the results from the OLS estimation. Column 1 reports the estimation with all fixed effects included; column 2 adds basic demographic characteristics (education, ethnicity, country of birth and partnership status) and an additional control variable (house prices); column 3 adds county-specific linear time trends; and column 4 adds age group-county-specific linear time trends.

The specification in the first column yields a positive and statistically insignificant coefficient of 0.008 . After adding more controls and time trends, the results consistently show that the overall unemployment rate is positively associated with fertility rates. To assess whether different age groups are more likely to move in response to an economic shock, I include age group-county-specific linear time trends in column 4. The coefficient of the main interest remains similar to the ones in columns 1-3, implying that age groups do not systematically move into different counties in response to adverse labor market conditions. According to the estimate from the fully saturated model in column 4, a 1 percentage point increase in the unemployment rate is associated with a $1.3 \%$ increase in birth rates, which is significant at the $1 \%$ level. This finding suggests that fertility moves countercyclically, and, accordingly the substitution effect dominates any negative income effect over the sample period. The main reasons for this finding are twofold: On the LFP side, the difference between the LFP of men and women has shrunk considerably since the mid-1990s. On the earnings side, the gender pay gap has been following a downward trend. ${ }^{20}$ Consequently, improvements in women's job opportunities and in wages have increased the opportunity cost of childbearing, causing fertility to move in the opposite direction to that of the business cycle. In order to address omitted variables biases,

20 More specifically, the LFP difference between men and women fell from $14.5 \%$ age points in 1994 to 8.6 percentage points in the final quarter of 2011. In terms of the gender pay gap, based on median hourly earnings excluding overtime, it has narrowed for full-time employees, to 9.1\% compared with $17.4 \%$ in 1997 . The gap for all employees has also followed a downward trend to $19.5 \%$, down from $27.5 \%$ in 1997. In addition, Polachek and Xiang (2014) find that the pay gap in England is declining relatively more quickly than in other countries. 


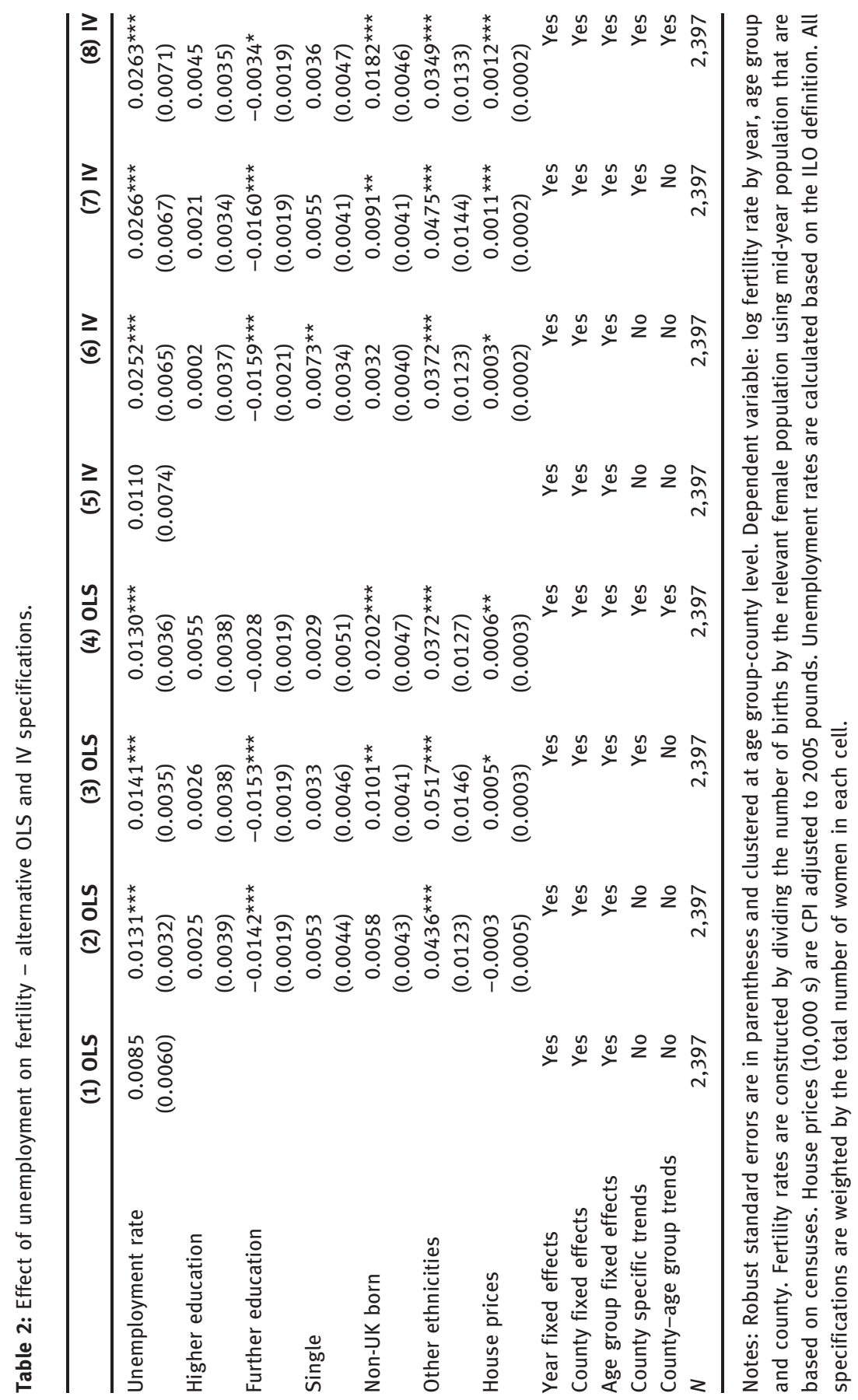


the rest of the analysis is carried out based on the specification in column 3 , in which I control for observable demographic characteristics and house prices. I also exploit the panel aspects of the data by including county and year fixed effects as well as the county-specific linear time trends.

The analysis continues with a stratification of the regressions with agespecific characteristics so as to gain further insight into the demographic basis of this result. The upper panel of Table 3 suggests that the fertility is the most responsive to unemployment rates between the ages of 25 and 34 . In this age group, a 1 percentage point increase in the unemployment rate leads to a $1.32 \%$ increase in fertility. The incidence of youth unemployment also has a positive and marginally significant impact on fertility. The older group, 35-44, by contrast, shows no significant impact of unemployment on birth rates. Altogether, the results in this table suggest that age groups react differently when they are exposed to local unemployment shocks. The next table, therefore, proceeds to further examine the age group-gender characteristics.

Table 3: Effect of unemployment on fertility - age group specifications.

\begin{tabular}{lrrr}
\hline & (1) & (2) & (3) \\
\hline & Aged 16-24 & Aged 25-34 & Aged 35-44 \\
\hline Unemployment rate & OLS & OLS & OLS \\
& $0.0044^{\star \star \star}$ & $0.0132^{\star \star \star}$ & 0.0011 \\
& $(0.0008)$ & $(0.0011)$ & $(0.0019)$ \\
\hline Unemployment rate & IV & IV & IV \\
Year fixed effects & $0.0087^{\star \star \star}$ & $0.0274^{\star \star \star}$ & $0.0068^{\star}$ \\
County fixed effects & $(0.0008)$ & $(0.0028)$ & $(0.0031)$ \\
County-specific trends & Yes & Yes & Yes \\
Demographic controls & Yes & Yes & Yes \\
House prices & Yes & Yes & Yes \\
$N$ & Yes & Yes & Yes \\
& Yes & Yes & Yes \\
\hline
\end{tabular}

Notes: Robust standard errors are in parentheses and clustered at county level. Dependent variable: log fertility rate by year, age group and county. Fertility rates are constructed by dividing the number of births by the relevant female population using mid-year population that are based on censuses. House prices $(10,000 \mathrm{~s})$ are CPI adjusted to 2005 pounds. Unemployment rates are calculated based on the ILO definition. All specifications are weighted by the total number of women in each cell. ${ }^{\star} p<0.1,{ }^{\star \star} p<0.05,{ }^{\star \star \star} p<0.01$. 
Table 4: Effect of unemployment on fertility - age group-gender specifications.

\begin{tabular}{lccr}
\hline & (1) & (2) & (3) \\
\hline & Aged 16-24 & Aged 25-34 & Aged 35-44 \\
\hline Male unemployment rate & OLS & OLS & OLS \\
& $-0.0011^{\star \star \star}$ & $-0.0089^{\star \star \star}$ & -0.0036 \\
Female unemployment rate & $(0.0003)$ & $(0.0029)$ & $(0.0054)$ \\
& $0.0044^{\star \star \star}$ & $0.0129^{\star \star \star}$ & 0.0038 \\
& $(0.0008)$ & $(0.0010)$ & $(0.0022)$ \\
\hline Male unemployment rate & IV & IV & IV \\
Female unemployment rate & $-0.0032^{\star \star \star}$ & $-0.0218^{\star \star \star}$ & -0.0189 \\
& $(0.0011)$ & $(0.0067)$ & $(0.0116)$ \\
Year fixed effects & $0.0099^{\star \star \star}$ & $0.0626^{\star \star \star}$ & $0.0483^{\star *}$ \\
County fixed effects & $(0.0032)$ & $(0.0099)$ & $(0.0063)$ \\
County-specific trends & Yes & Yes & Yes \\
Demographic controls & Yes & Yes & Yes \\
House prices & Yes & Yes & Yes \\
$N$ & Yes & Yes & Yes \\
\hline
\end{tabular}

Notes: Robust standard errors are in parentheses and clustered at county level. Dependent variable: log fertility rate by year, age group and county. Fertility rates are constructed by dividing the number of births by the relevant female population using mid-year population that are based on censuses. House prices (10,000s) are CPI adjusted to 2005 pounds.

Unemployment rates are calculated based on the ILO definition. All specifications are weighted by the total number of women in each cell. ${ }^{*} p<0.1,{ }^{* *} p<0.05$, ${ }^{* *} p<0.01$.

The differences between age- and gender-specific unemployment rates are highlighted in Table 4 in which I expect to find that female unemployment will be positively associated with fertility, whereas male unemployment will have the opposite impact. Overall, the results are in line with this notion. For example, a 1 percentage point increase in female unemployment leads to a $1.29 \%$ increase in births for the prime age group. For men, the negative and significant effects are concentrated among the younger cohorts, $16-24$ and 25-34. However, for the age group 35-44, there are insignificant coefficients on unemployment for both males and females. This finding could be because there is a weak relationship between older cohorts' fertility decision and their labor market status. The following section of the paper is concerned with endogeneity of unemployment, and IV estimation results are presented. 


\subsection{Estimation}

As discussed in Section 3.2, the potential sources of bias in the OLS results are the possibility of reverse causality and/or some unobservables that are affecting fertility rates other than unemployment. I start by considering the full sample and estimate the effect of overall unemployment (aged 16-44) on fertility. Confirming the OLS findings in Table 2, columns 1-4, I find that the IV coefficients have the same sign; however, they are larger in magnitude. In the first stage, the predicted unemployment rates are significantly correlated with the endogenous variable and in the expected direction. Since the IV estimates can be interpreted as the impact of a fall in local labor demand on fertility, finding higher coefficients suggest that these estimates reflect the local spillovers in unemployment. In other words, they capture: (1) the main effect due to being unemployed, (2) the risk of being in unemployed in the near future and (3) expectations about future wage growth.

In order to quantify the different effects of the predicted unemployment rate, I proceed to separately estimate the relationship across age groups and age group-gender cohorts. In Table 3, the point estimates on age groups are all positive and statistically significant at conventional levels. Column 2, in bottom panel of Table 4, strongly confirms previous findings that male and female unemployment have different impacts on fertility and reveals the importance of sub-group characteristics. In parallel to the main hypothesis of this paper, the results imply that a one percentage point increase in male unemployment leads to a $2.18 \%$ decrease in birth rates whereas same amount of increase in female unemployment leads to a $6.26 \%$ increase in birth rates for the age group 25-34. This shows that the positive effect of female unemployment on fertility is much larger for prime aged women. The results for men again show that unemployment has a significant negative effect on fertility, with the effect being stronger at later ages. Taken together, these results suggest that unemployment is an important determinant of fertility behavior. The following part of the results proceeds to explore whether the responses are homogenous across demographic characteristics.

\subsection{Analysis by Demographic Characteristics}

Having detailed information in UK LFS enables a filtering out of the effects of unemployment on fertility by education, country of birth and marital status. In order to allow the point estimates on county and year fixed effects to vary across subgroups, I construct covariates and estimate the relationship for each age 
group. In Table 5, columns 1-3 present estimates for the OLS specifications and columns 4-6 present estimates for the IV specifications. Because the cell size in industry employment composition by demographic characteristics is small at baseline, some IV estimates have lower number of observations. However, this does not cause excluded variables to show a weak partial correlation with unemployment. Although not reported due to space restrictions, the values for first-stage $F$-statistics are consistently higher than 10 . Nonetheless, one caveat is that the measurement error of group-specific unemployment rates may lead to biased estimates, so these results should be interpreted with caution.

Looking at the estimates presented by educational attainment in Panel (A) of Table 5, I find that the coefficients on unemployment are negative and significant for the 16-24 age group, but they are positive for older cohorts who are highly educated. In the further education category, unemployment also seems to be positively associated with fertility. The fact that the effect is more pronounced on the degree level may be attributable to the fact that women take advantage of the low opportunity cost of childbearing to prevent future career interruption which occurs due to the transition to motherhood. The IV estimates again are larger in magnitude and tend in the same direction.

Panel B shows results separately for UK-born and non-UK-born cohorts. Coefficients on unemployment for non-UK borns in both OLS and IV estimations are negative and mostly larger in magnitude. This result may be explained by the fact that immigrants are more sensitive to cyclical increases in unemployment than those of natives. For UK borns, the effects of unemployment on fertility tend to be positive.

Turning now to the evidence on partnership in panel (C), I detect clear differences by marital status. Contrary to my expectations, I find that unemployment has a only negligible influence on fertility at younger ages, but it exhibits stronger association among older cohorts. Indeed, the coefficient of unemployment is negative and significantly different from zero for singles at more advanced ages. Looking at the results for married cohorts, unemployment is positively associated with fertility and the effect is mostly concentrated at the prime age cohort.

\subsection{Robustness Checks}

Additional robustness checks are conducted in order to detect whether the main findings remain stable to different specifications. The first column in Table 6 presents results for teenage fertility. Results in the upper panel of column 1 indicate that unemployment has a positive and marginally significant impact on 


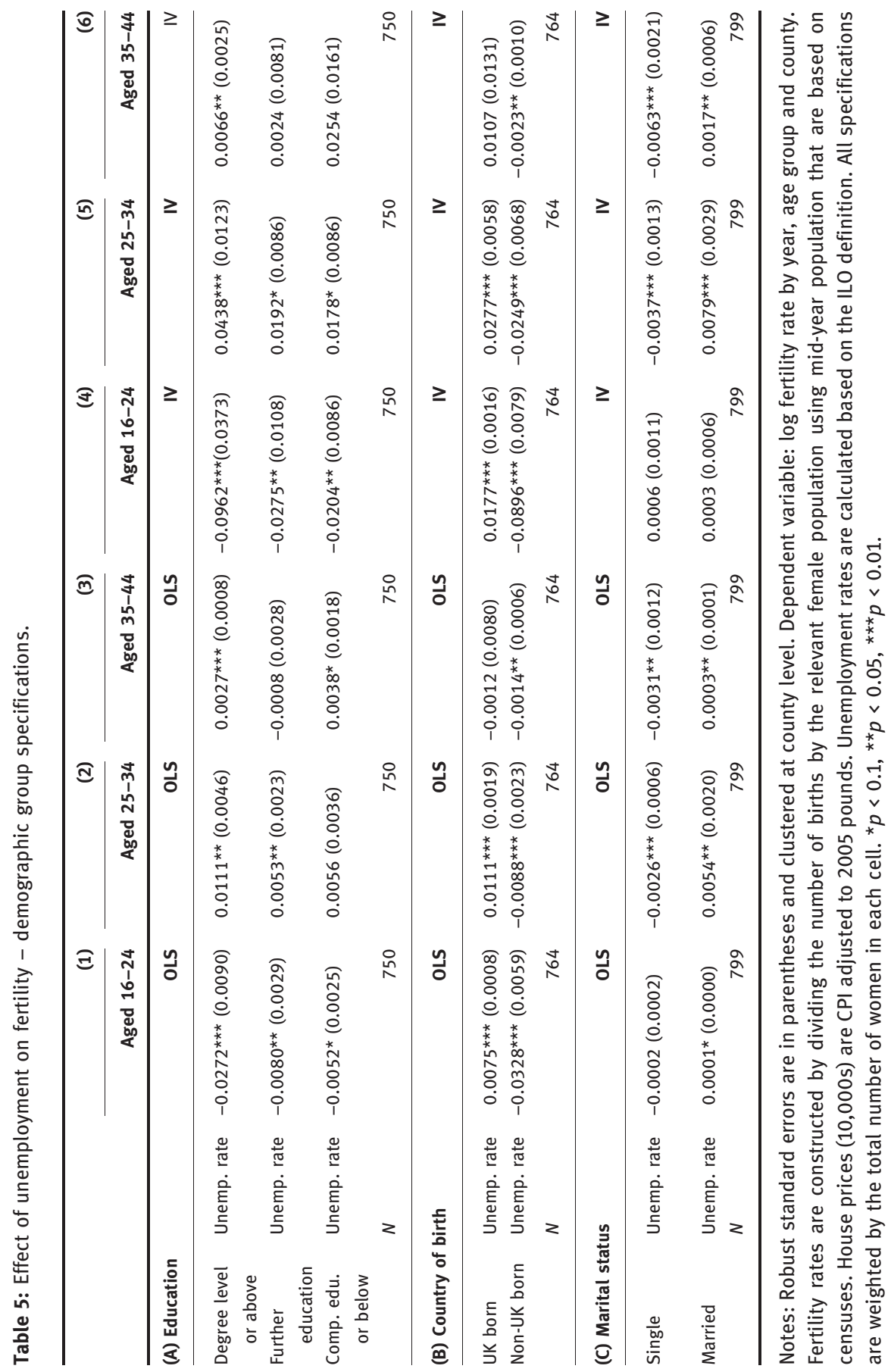




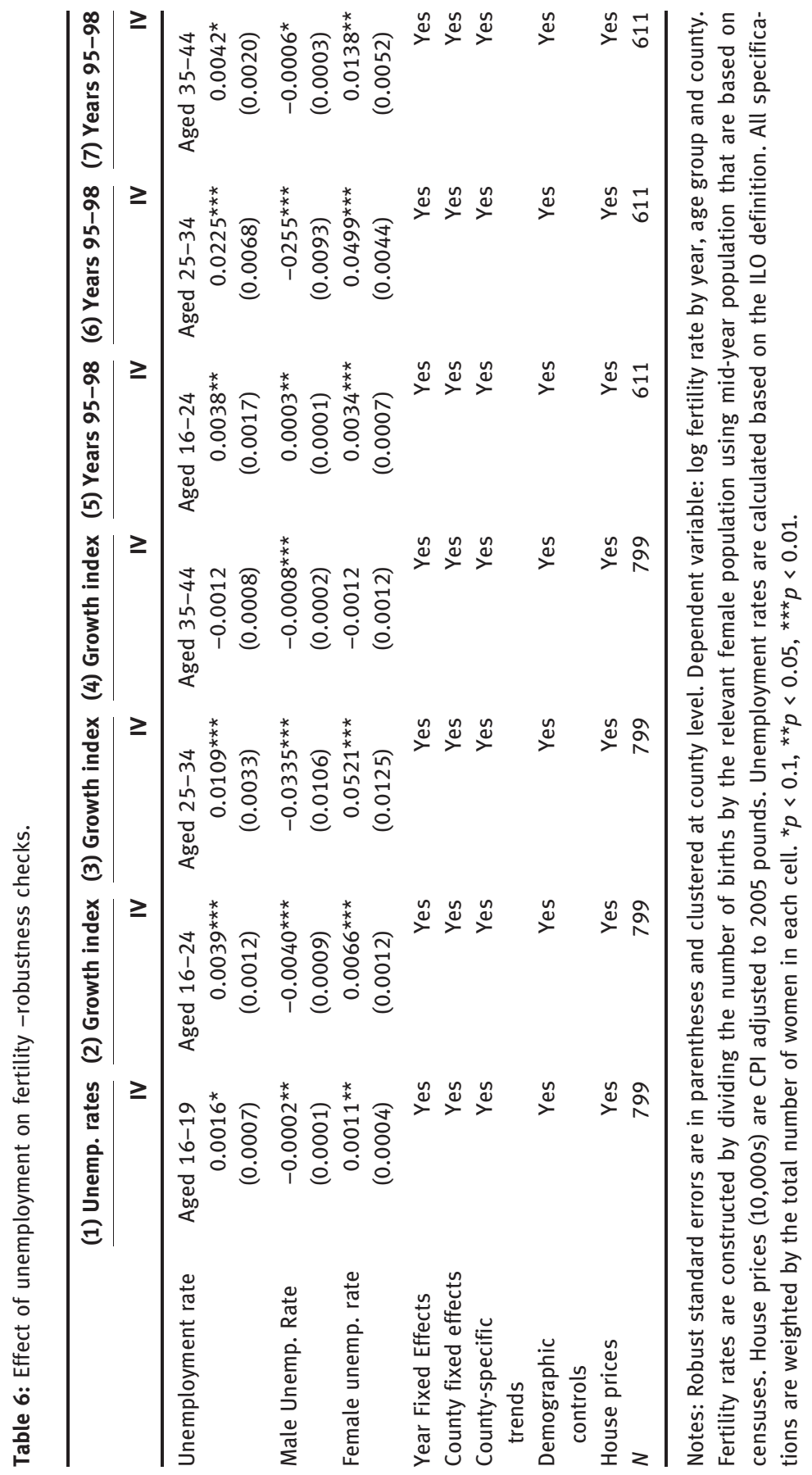


birth rates. As can be seen from the bottom panel, both male and female unemployment maintain the expected signs of direction. Although the effects are small in magnitude, the results are still in line with the main findings of this paper.

Between columns 2 and 4, I further discuss the important issue of the validity of my instrument, which is introduced in Section 4.2. The strong correlation of my instrument with the endogenous variable is apparent from all the first-stage results presented in Appendix Table 7. Although the IV results seem robust to a number of alternative specifications, one may argue that unemployment is not necessarily a purely demand-driven measure and is also affected by the changes in labor supply. Finally, I build on my instrument and use employment growth index as an alternative measure to assess the robustness of my results. The measure reflects exogenous labor demand for females and males in each age group and is constructed as follows: for each county, age group and year, I start with a variable measuring the proportion of employment based on local industry structure at baseline. Next, similar to Aizer (2010), I construct an annual employment growth index for each gender and age group, by interacting baseline measure with national trends in employment growth rates in industries dominant in the county, then collapsing over industries within each countyyear-age group cell:

$$
\text { Emp Growth } \text { ghjt }=\sum_{k} \Psi_{g h j k} \text { EMPGROWTH }_{g h k t}
$$

where $\psi_{g h j k}$ is the share of industry $k$ among employed individuals of age group $g$, gender $h$, county $j$ at baseline, and where EMPGROWTH $\mathrm{E}_{\text {ghkt }}$ is the industry employment growth rate, at the national level, in industry $k$ for individuals of age group $g$, gender $h$ and in time period $t$. The first-stage results show that all measures of unemployment are well correlated with the instruments. However, the Kleibergen-Paap $F$ statistic points to a weak identification issue for those aged 35-44, so that coefficients may suffer from bias and should be interpreted with caution. On the whole, the IV estimates presented in Table 6 alleviate concerns about the biased estimates induced by the changes in labor supply and are consistent with the baseline results. Reassuringly, I find that: (1) fertility moves countercyclically over the business cycle; (2) the prime age group is more responsive to changes in unemployment; (3) male unemployment is negatively and female unemployment is positively associated with births, with these effects often being smaller and mostly significant. Finally, the results introduced in columns 5-7 show that the outcome is not driven by the serial correlation and present estimates after dropping the first 4 years of the sample. Across all age groups, the coefficients consistently remain qualitatively unchanged. Taken 
together, I obtain results that are very similar to the baseline estimates and provide meaningful insights on the countercyclical nature of births along with group-specific differences across social strata in England.

\section{Conclusion}

The aim of this study was to assess the causal effect of unemployment on fertility in England and to evaluate how this effect varies across sub-demographic groups. Its main finding is that the substitution effect dominates the income effect at the aggregate level, implying a countercyclical fertility pattern that may be attributable to changes in female labor market outcomes over the sample period. Additionally, the relevance of gender-specific unemployment is clearly supported by the current findings and the results confirm the main predictions of dynamic fertility models. The findings indicate that female unemployment tends to increase fertility, as women take advantage of the low opportunity cost of childbearing in the form of mothers' time. Male unemployment goes in the opposite direction, which implies an income effect. Returning to the questions posed at the beginning of this study, it is now possible to state that a comparison of age groups reveals that unemployment is more likely to affect the fertility of younger cohorts, rather than older ones. A speculative reason for this is the possibility that the former are more able to postpone their fertility until economic conditions recover, while labor market conditions may play a less important role for couples whose "fertile" lifetime is nearing its end. The expected variation in the unemployment and fertility relation by educational attainment, marital status and country of birth is also documented. Although the study has successfully demonstrated the aforementioned findings, it is however limited by the use of total birth rates, and the findings cannot be transferable to birth orders. Future research should therefore concentrate on the investigation of birth orders while considering demographic subgroup characteristics.

All in all, the present study confirms previous findings and provides additional evidence suggesting the existence of strong variation across sub-demographic groups, while showing that different age groups and genders react differently to local unemployment shocks.

Acknowledgments: The author would like to express his thanks to the Editor, Robert Fleck, as well as anonymous referees for their helpful comments and suggestions. The paper also benefited from the insightful comments of Dan Anderberg, Arnaud Chevalier, Dan S. Hamermesh and Andrew Seltzer. 


\section{Appendix Figures}
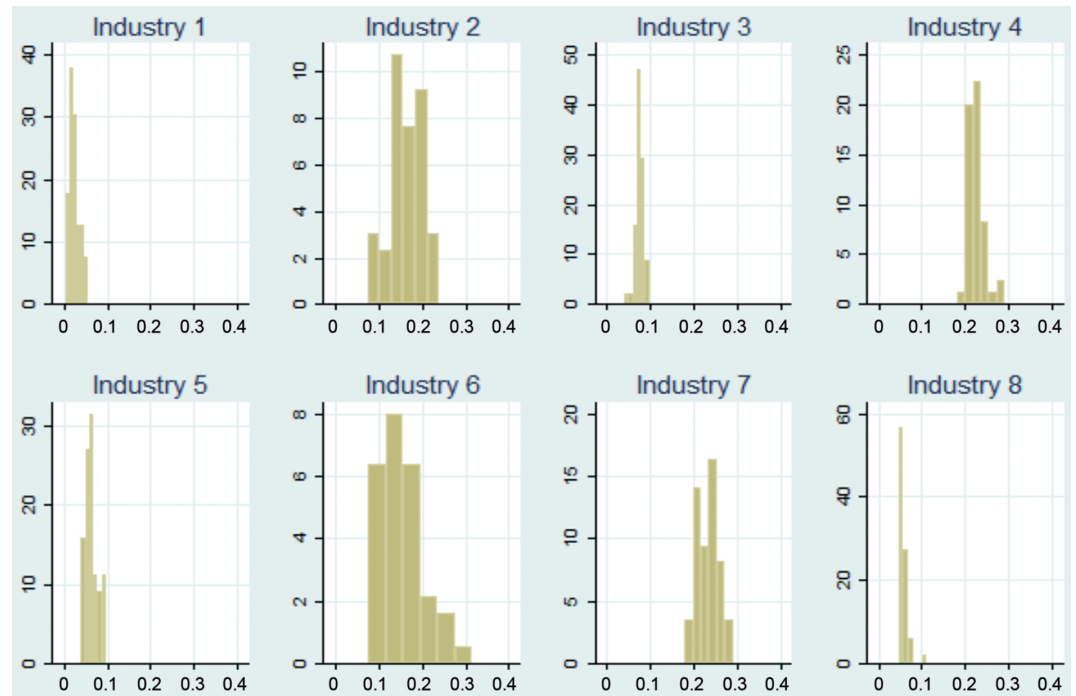

Figure 3: Share of each industry across counties.
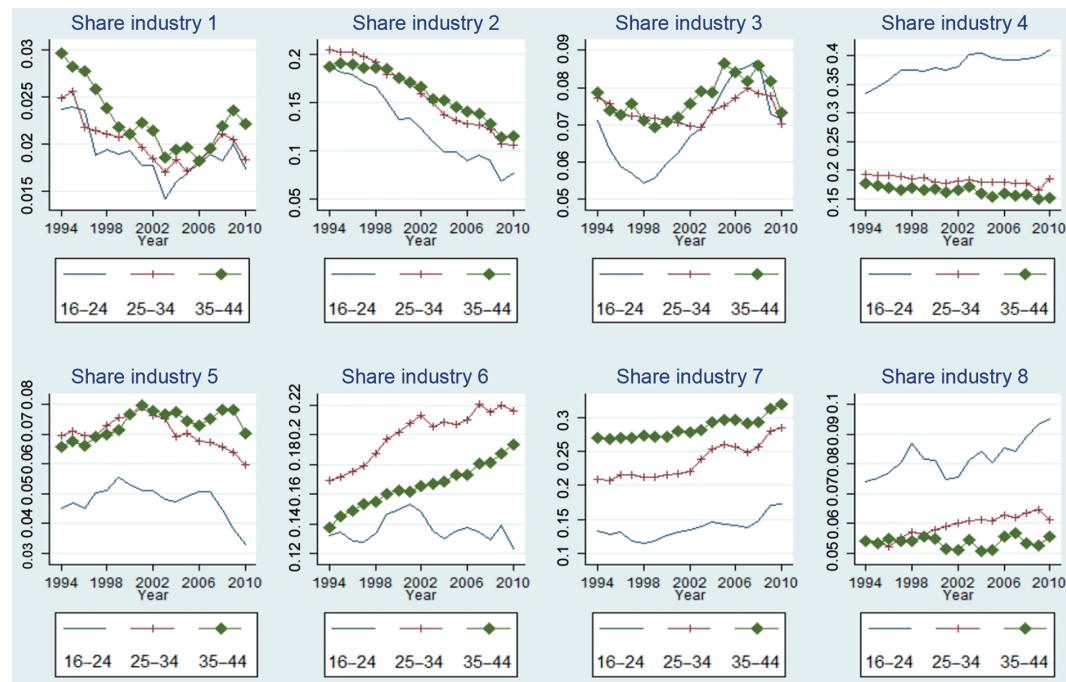

Figure 4: Industry composition across age groups.

Notes: Industry: 1, agriculture industry; 2, manufacturing industry; 3, construction industry; 4, distribution/hotel/restaurant industry; 5, transport and communications industry; 6, banking/ finance/insurance industry; 7 , public administration/education/health industry; 8 , other services. 


\section{Appendix Table}

Table 7: First-stage estimations.

\begin{tabular}{|c|c|c|c|c|}
\hline & (1) & (2) & (3) & (4) \\
\hline & Aged 16-44 & Aged $16-24$ & Aged 25-34 & Aged 35-44 \\
\hline & First stage & First stage & First stage & First stage \\
\hline \multirow{2}{*}{$\begin{array}{l}\text { Predicted } \\
\text { unemployment rate }\end{array}$} & $1.094^{\star \star \star}$ & $1.107^{\star \star \star}$ & $0.0995^{\star \star \star}$ & $1.042^{\star \star \star}$ \\
\hline & $(0.0333)$ & $(0.0388)$ & $(0.0226)$ & $(0.0229)$ \\
\hline Year fixed effects & Yes & Yes & Yes & Yes \\
\hline County fixed effects & Yes & Yes & Yes & Yes \\
\hline Age group fixed effects & Yes & No & No & No \\
\hline County-age group trends & Yes & No & No & No \\
\hline County-specific trends & Yes & Yes & Yes & Yes \\
\hline$N$ & 2,397 & 799 & 799 & 799 \\
\hline First-stage $R 2$ & 0.901 & 0.764 & 0.836 & 0.809 \\
\hline First-stage $F$ statistic & 29.60 & 24.52 & 51.32 & 54.91 \\
\hline
\end{tabular}

Note: Dependent variable: unemployment rate by year, age group and county. ${ }^{*} p<0.1,{ }^{\star \star} p<$ $0.05,{ }^{* *} p<0.01$.

\section{References}

Adsera, A. 2005. "Vanishing Children: From High Unemployment to Low Fertility in Developed Countries." American Economic Review 95 (2): 189-93.

Ahn, N., and P. Mira. 2002. "A Note on the Changing Relationship between Fertility and Female Employment Rates in Developed Countries." Journal of Population Economics 15 (4): 667-82.

Aizer, A. 2010. "The Gender Wage Gap and Domestic Violence." The American Economic Review 100 (4):1847.

Anderberg, D., H. Rainer, J. Wadsworth, and T. Wilson. 2015. "Unemployment and Domestic Violence: Theory and Evidence." The Economic Journal. http://onlinelibrary.wiley.com/doi/ 10.1111/ecoj.12246/abstract.

Bartik, T. J. 1991. Who Benefits from State and Local Economic Development Policies? Kalamazoo, MI: W.E. Upjohn Institute for Employment Research.

Becker, G. S. 1960. “An Economic Analysis of Fertility.” In Demographic and Economic Change in Developed Countries, National Bureau of Economic Research (ed.) 209-31 (NBER Conference Series vol 11). Princeton: Princeton University Press.

Becker, G. S., and H. Gregg Lewis. 1973. "On the Interaction between the Quantity and Quality of Children.” Journal of Political Economy 81 (2): S279-88.

Black, D. A., N. Kolesnikova, S. G. Sanders, and L. J. Taylor. 2013. "Are Children "Normal”?" The Review of Economics and Statistics 95 (1):21-33. 
Blanchard, O. J., and L. F. Katz. 1992. "Regional Evolutions.” Brookings Papers on Economic Activity 23:1-75.

Brewster, K. L., and R. R. Rindfuss. 2000. “Fertility and Women's Employment in Industrialized Nations." Annual Review of Sociology 26:271-96.

Butz, W. P., and M. P. Ward. 1979. "The Emergence of Countercyclical US Fertility." The American Economic Review 69 (3): 318-28.

Dettling, L. J., and M. S. Kearney. 2014. "House Prices and Birth Rates: The Impact of the Real Estate Market on the Decision to Have a Baby." Journal of Public Economics 110:82-100.

Easterlin, R. A. 1973. "Relative Economic Status and the American Fertility Swing.".

Engelhardt, H., and A. Prskawetz. 2004. "On the Changing Correlation between Fertility and Female Employment Over Space and Time." European Journal of Population/Revue Européenne De Démographie 20 (1):35-62.

Esping-Andersen, G. 2009. Incomplete Revolution: Adapting Welfare States to Women's New Roles. Polity.

Happel, S. K., J. K. Hill, and S. A. Low. 1984. "An Economic Analysis of the Timing of Childbirth." Population Studies 38 (2):299-311.

Heckman, J. J., and J. R. Walker. 1990. "The Relationship Between Wages and Income and the Timing and Spacing of Births: Evidence from Swedish Longitudinal Data." Econometrica: Journal of the Econometric Society 58 (6): 1411-41.

Jones, L. E., A. Schoonbroodt, and M. Tertilt. 2008. "Fertility Theories: Can They Explain the Negative Fertility-Income Relationship?. No. W14266.” National Bureau of Economic Research.

Örsal, K., D. Dilan, and J. R. Goldstein. 2010. The increasing importance of economic conditions on fertility. No. WP-2010-014. Max Planck Institute for Demographic Research, Rostock, Germany.

Kravdal, Ø. 2002. "The Impact of Individual and Aggregate Unemployment on Fertility in Norway." Demographic Research 6 (10):263-94.

Lindo, J. M. 2010. "Are Children Really Inferior Goods? Evidence from Displacement-Driven Income Shocks." Journal of Human Resources 45 (2):301-27.

Mincer, J. 1963. "Market Prices, Opportunity Costs, and Income Effects." In Measurement in Economics, edited by C. Christ et al., 67-82. Stanford, Calif.: Stanford University Press.

Ozcan, B., K. U. Mayer, and J. Luedicke. 2010. "The Impact of Unemployment on the Transition to Parenthood." Demographic Research 23 (29):807-46.

Polachek, S. W., and J. Xiang. 2014. "The Gender Pay Gap across Countries: A Human Capital Approach.” IZA Discussion Paper, no. 8603.

Schaller, J. 2015. "Boom, Busts, and Fertility: Testing the Becker Model Using Gender-Specific Labor Demand." Davis: University of California-Davis.

Sobotka, T., V. Skirbekk, and D. Philipov. 2011. "Economic Recession and Fertility in the Developed World." Population and Development Review 37 (2):267-306.

Willis, R. J. 1973. "A New Approach to the Economic Theory of Fertility Behavior." The Journal of Political Economy 81 (2): 14-64. 